The article "Personal coaching: A model for effective learning" (Griffiths, 2006) appeared in the Journal of Learning Design Volume 1, Issue 2 in 2006. Almost ten years on, Kerryn Griffiths reflects upon her original article.

\title{
Personal coaching: Reflection on a model for effective learning
}

\author{
Kerryn Griffiths \\ Personal Coach \\ Northern New South Wales \\ AUSTRALIA \\ kerryn@kerryngriffiths.com
}

When I first embarked on my research into coaching as a model for effective learning back in 2005, the presence of coaching in educational contexts was minimal. At the time, my paper proposed personal coaching to be a model for active, collaborative, authentic and engaging learning that courageously challenged and moved beyond more conventional transmission models of learning. I had seen how willingly my coaching clients were engaged in learning and I could not ignore the contrast with the lack of engagement and resistance among my classroom students. I knew that learning was inherent within the coaching process and I wanted to understand how; so that the process may be applied more widely within educational contexts.

At the time, it was clear that coaching had its roots in adult learning theory and lifelong learning, that it mirrored the process of transformational learning and that it also made use of processes relating to experiential learning and mentoring theory. However, my later research revealed that the process of coaching in fact facilitated a dynamic interchange between no less than 18 learning theories including: collaborative learning, mentoring, self-directed learning, social learning, reflective learning, adult learning, experiential learning, transformative learning, deep learning, authentic learning, action learning, inductive learning, discovery learning, powerful learning, lifelong learning, accelerated learning, problem-based learning and emotional intelligence.

In my original paper (Griffiths, 2006), I suggested a combined coaching-learning model which required a shift in educational approach from a curriculum top-down model to a "coach approach," with students' personal goals at its pinnacle. I suggested that a coach approach to education would be one where learning was driven by students' personal goals and their intrinsic need to know. It would be embedded in the real context of their lives and accompanied by a partner in the learning journey, namely a coach. Now, ten years later, I now recognise the idealism of youth!

Fortunately, my later research into the learning process in coaching led to the identification of a much more achievable integration of coaching processes into educational and learning contexts. The findings of my study revealed that there are three major stages of learning involved in coaching, namely, discovery, application and integration. The processes of relating, questioning, reflecting and listening led to the discoveries while the processes of accountability and action led to the application of the discoveries. Finally, by taking responsibility and self-coaching, the learning was fully integrated. Self-knowledge was woven throughout but the findings also indicated that the type of knowledge generated by coaching might be determined by the kind of coaching goal. As my research looked at personal coaching and therefore personal goals, self-knowledge was the natural outcome. Another kind of coaching such as business coaching with business goals would be likely to result in a different kind of knowledge such as business knowledge. Put simply, the goal determined and shaped the outcome. 
Now I look back on the combined coaching-learning model I suggested in my original paper and compare it to the process of learning in coaching I uncovered during my later research (see Griffiths \& Campbell, 2009). I also reflect on the later work I did in vocational education where I actively used the coaching learning processes to patch educational gaps (and heal emotional wounds) left in adults after more than a decade of traditional schooling. In the light of this reflection, I would now propose a different combined coaching-learning model (see Figure 1).

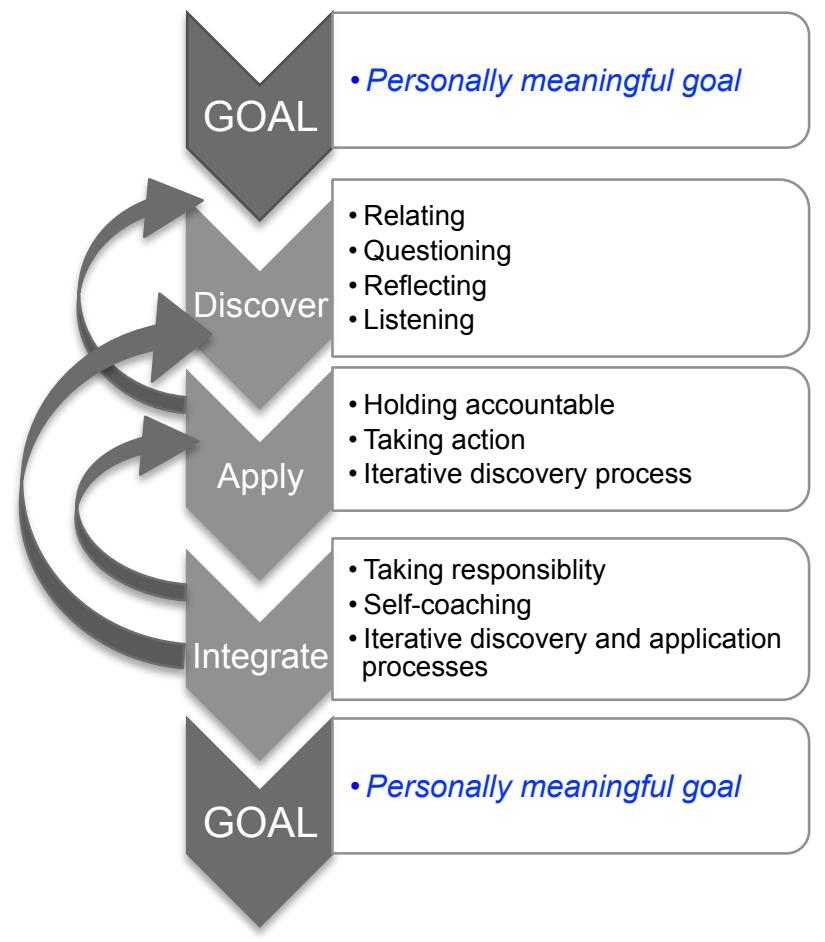

Figure 1: Combined Coaching-Learning Model

Figure 1 illustrates how the coaching learning processes of discovery, application and integration begin and end with a personally meaningful goal. Therefore, students' personal goals still determine the direction of learning, rather than a curriculum. The school teacher in me says this is impossible but the vocational trainer in me knows how possible it is.

The course of learning is directed by the students' personally meaningful goals. In their pursuit of these goals, they discover new knowledge, apply it to their personally meaningful contexts and eventually integrate it so it becomes part of who they know themselves to be and what they are capable of. Typically, the result of this is the achievement of, or advancement towards, their personally meaningful goals. The discoveries are made through trusted learning relationships and driven by questioning, usually beginning with the teacher/coach but later, expanded by other learning partners, such as fellow students and mentors, and also continued by questioning the self (selfcoaching). Reflection and listening result in learning and, importantly, the recognition of the learning itself. This learning is then applied through accountability and action and, as the student takes responsibility, it is integrated into their sense of self. Self-coaching eventually takes over to create a truly self-directed learning environment. Finally, not unlike the process of the recognition of prior learning, learning is then back-tracked against the curriculum. Rather than a desired set of skills and knowledge driving the learning experience, instead the skills and knowledge are drawn from the learning experience. 


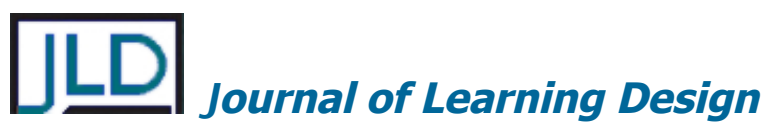

I have been informed that my original paper had one of the highest number of downloads for this journal in the last ten years. This encourages me for two reasons. Firstly, I believe it highlights the growing interest in, and application of, coaching within educational and learning contexts. Secondly, I have hope that it highlights a possible emergent shift away from a curriculum led model of education to one in which learning is driven by, and drawn from, the experience and pursuit of learners' personally meaningful goals. 


\title{
Personal coaching: A model for effective learning
}

\author{
Kerryn Griffiths \\ Centre for Learning Innovation \\ Queensland University of Technology, AUSTRALIA \\ k4.griffiths@student.qut.edu.au
}

\begin{abstract}
The escalating success of personal coaching and the significant potential it holds as a vehicle for effective learning, appear to have had little impact within educational contexts to date. In response, this paper therefore presents an introduction to personal coaching practice and its outcomes and examines its processes through a discussion of learning theory. In doing so, it demonstrates the learning value inherent within the coaching framework and challenges educators to consider its potential as a model for active, collaborative, authentic and engaging learning.
\end{abstract}

\section{Keywords}

Personal Coaching, life coaching, professional coaching, learning, adult learning, lifelong learning, transformational learning, experiential learning

\section{Introduction}

Despite the explosive emergence of personal coaching throughout the last decade, formal educational contexts are yet to tap into its potential as a vehicle for effective learning. Surfacing as a popular profession in the United States in the late 1980s (Results Coaching Systems, 2004) and fuelled by a massive billion dollar self-help industry, the booming growth of coaching is second only to that of the IT industry (Wilkins, 2000; Zeus \& Skiffington, 2002). Personal coaching is occupying a growing presence in newspapers, magazines and trade journals (Hargrove, 2003) and whilst the body of evidence-based literature around coaching remains small, there has been a three-fold surge in peerreviewed studies into coaching just in the last ten years (Grant, 2003a). Current studies come mostly from the behavioural sciences as well as business and organisational sectors with the latter often being linked to adult education and lifelong learning, within both evidence-based coaching texts (Zeus \& Skiffington, 2002) in addition to empirical studies (Hurd, 2002; Wilkins, 2000). It seems everyone is jumping on the coaching "bandwagon" - that is, everyone except formal educational settings, namely schools, colleges and universities. Surprisingly, this is despite the recognition of learning being "at the heart of coaching" (Skiffington \& Zeus, 2003, p. 30) and despite technical and empirically based descriptions of coaching as "a vehicle and a platform for learning" (Zeus \& Skiffington, 2002, p. 20), a "holistic multifaceted approach to learning and change" (Skiffington \& Zeus, 2003, p. 30), a "forum for learning" (Creane, 2002, p. iv) and a "personal education pathway" (Duff, 2002, p. 7). In the light of this, this paper therefore provides an overview of personal coaching practice and its outcomes of delivering personal and professional change. It then highlights its limited understanding within educational contexts and counteracts this by exposing the inherency of learning within the coaching process by linking it to established bodies of learning theory. In doing so, it culminates in a proposal of personal coaching as a model for active, collaborative, authentic and engaging learning that courageously challenges and moves beyond more conventional transmission models of learning. 


\section{What is personal coaching?}

There is considerable confusion surrounding the understanding of what coaching is in both literature and in the eyes of educators. This confusion has perhaps arisen due to the historical origins of the word "coach," the presence of some related forms of coaching within educational settings such as cognitive, peer and academic coaching as discussed later, and also because of the various roles coaches assume during the coaching process in addition to the disciplinary roots from which coaching is derived. Not unlike the multiple roles managed by educators (Keenan \& Braxton-Brown, 1991), a 1998 survey of coaching clients (International Coach Federation, 1998) reflected various depictions of the roles of a coach from that of a sounding board and motivator to that of a mentor, consultant, teacher, taskmaster or spiritual guide. Whilst coaching is, in general, often misinterpreted as a form of therapy, training/consulting/tutoring or mentoring (Grant, 2001a; Zeus \& Skiffington, 2002), the key distinction between coaching and other "helping roles" including that of teachers is the coaching expectation of the achievement of specific goals and a solid commitment to planned action (Zeus \& Skiffington, 2002). This is in contrast to therapy which focuses on personal and emotional healing (Grant, 2001a) and consulting, training, tutoring and teaching which all focus on curriculum, content and competencies (Grant, 2001a; Olivero, Bane \& Kopelman, 997; Zeus \& Skiffington, 2002). Furthermore, while mentoring and often teaching are characterised by an expert-novice relationship, both technical and empirical coaching literature emphasise the existence of an equal partnership between coach and client (Grant, 2001a; Hurd, 2002; Richardson, 2000; Whitworth, Kimsey-House \& Sandahl, 1998).

With the body of empirical coaching literature still in its infancy (Grant, 2001a; Zeus \& Skiffington, 2002), coaching has been allowed to flourish over the last decade without a designated governing body or an established theoretical framework. It thus exists in many forms. Executive coaching is by far the most dominant form in the marketplace and in current research and provides the platform from which personal coaching has evolved. It is this form of coaching, having stemmed from commercial realms but translated into individual personal contexts, which is examined in this paper. The most common approaches used by coaches are goal-directed coaching and facilitation and process oriented coaching (Bono, Purvanova \& Towler, 2004). The International Coach Federation (2004), the self-evolving international regulatory body of coaching, identifies this approach as one of its four core coach competencies, namely "facilitating learning and results." As explained within this competency, it is the responsibility of coaches to facilitate the development of goals and the designing of actions that lead to the achievement of these goals. Furthermore, coaches must help to create client awareness to promote learning and development and finally generate the self-directed and self-regulated progress of clients by tracking their progress and managing accountability.

As Grant (2001a) explained, goal setting ignites the coaching cycle. This is followed by focused, planned action toward the achievement of the goals which in turn utilises various methods of observation, assessment and analysis to monitor and evaluate situations prevailing in clients' lives. Then, by capitalising on their inherent creativity and potential, clients' realities are expanded towards a future vision. Finally, maintenance, support structures and constructive evaluation and feedback complete the coaching cycle in the achievement of goals. Whilst this is a broad framework within which coaching occurs, there are also common elements of coaching processes which have been shown to lead to successful coaching outcomes. Experience-based coaching theory (Evered \& Selman, 1989; Whitmore, 2002; Whitworth et al., 1998) and empirical studies arising from organisational learning, business and psychological contexts (Bono et al., 2004; Creane, 2002; Gale, Liljenstrand, Pardieu, \& Nebeker, 2002; Grant, 2001b; Hurd, 2002; Joy, 2001; Quick \& Macik-Frey, 2004; Wilkins, 2000) show that these include: power, trust, confidentiality and communication within a coaching partnership; coaches' multi-level, active engagement in deep listening; coaches' ability to generate powerful questions; feedback (self-generated or coach-generated); self-regulated and self-monitored movement through the coaching cycle; generation of self-evaluation and self-awareness; sustaining the client's agenda, accountability and responsibility; the development of problem-solving techniques; the 
provision of a support system for concrete action and practice; and, dealing with aspects of selfsabotage, resistance and emotions. Such principles are rooted in an almost inexhaustible array of disciplines. These include: sports psychology, personal development, clinical psychology, therapy, management development, sociological change, leadership and organisational development and education and adult learning (Hurd, 2002; Results Coaching Systems, 2004; Skiffington \& Zeus, 2003). In short, coaching can be described as a pro-active synthesis of centuries of acquired multidisciplinary understanding with learning at its centre.

The outcomes of coaching are wide and varied. Goal-specific coaching outcomes occur commonly in the areas of time-management, career, business, relationships/family, physical/wellness, spiritual, personal, goal-setting and financial issues (International Coach Federation, 1998). However a range of qualitative and quantitative studies demonstrate universal outcomes of coaching regardless of the content area, highlighting a consensus in what clients consistently derive from a coaching experience. In summary, this includes: heightened self-awareness, self- acceptance and a sense of well-being; improved goal-setting and goal attainment, life balance and lower stress levels; increased selfdiscovery, self-confidence and self-expression; better communication and problem-solving skills; enhanced quality of life; and, changed and broader perspectives and insight. Furthermore, clients repeatedly report better reception and use of feedback, better understanding of consequences of actions, practical application of theory, more effective thinking strategies, changes in behaviour, increased awareness of wants, present-focus, the ability to identify challenges and blocks, a deeper sense of self and generally functioning as a better person (Campbell \& Gardner, 2003; Creane, 2002; Duff, 2002; Grant, 2001b, 2003b; Hurd, 2002; International Coach Federation, 1998; Paige, 2002; Quick \& Macik-Frey, 2004). Thus it is clear that coaching not only enhances life experience but also opens up doors for personal transformation. It provides individuals with an opportunity to explore various dimensions of themselves and their experiences. It combines multi-disciplinary understanding within a goal- directed framework of focused, planned action and facilitates both learning and results through a precise orchestration of self-regulated accountability, powerful questioning and activelistening. Finally, it is this process, giving way to such outcomes, which, as explained in the following pages, is only made possible through a process of learning.

\section{Coaching in educational settings}

The presence of coaching in educational contexts is minimal. While several studies reflect on learning organisations within corporate sectors (Ellinger \& Bostrom, 1999; Hurd, 2002; Paige, 2002) and executive coaching has been recognised as a leadership and self-preservation tool for school principals (Hogan, 2004; Killion, 2002), the only known studies of personal coaching in formal education settings such as schools, colleges and universities is Campbell and Gardner's (2003) research into the impact of life coaching on Year Twelve students and Grant's (2003b) study of the impact of a life coaching program among post-graduate students. While Campbell and Gardner's (2003) mixedmethod study indicated that life coaching "may have potential for building resilience and wellbeing in young people" (p. 10), Grant's (2003b) study demonstrated that a combined cognitive-behavioural coaching model had greater impact upon goal attainment, metacognition and mental health than either a cognitive or behavioural coaching model.

There are also some branches of coaching present and active within educational contexts. For example, cognitive coaching is frequently used to assist teachers in delving into the thinking behind their practices. It encourages self-monitoring, self-analysis and self-evaluation of teaching practices in order to maximise student learning (Costa, 1992, 2000; Costa \& Garmston, 1994; Garmston, 1993). Peer coaching is also prevalent in formal education settings in two forms: expert coaching and reciprocal coaching. Expert coaching comprises of an unequal relationship involves feedback, support, alternatives and suggestions, while reciprocal coaching comprised of an equal relationship involves observation, feedback, support and natural learning (Zeus \& Skiffington, 2002). In addition, academic coaching has been loosely applied in educational contexts sometimes being synonymous with 
professional tutoring and cramming (Bagnall, 1999; Weiser, 1998), whereas Dansinger (2000) uses it as an alternative psychotherapy approach with gifted students experiencing problems at school.

Finally, there is a new move in educational settings to redefine the role of the teacher from that of instructor to one of facilitator (Keenan \& Braxton-Brown, 1991) particularly within the areas of information technology (Hollum \& Gahala, 2001; Snyder, 1996). This changing role is in fact characterised by an adoption and use of combined coaching strategies such as self-regulation, the use of questioning, problem-solving opportunities and feedback as "coaches guide students' inquiry in a student- directed environment" (Snyder, 1996, p. iv). Thus the role of the teacher is already moving towards coaching (Passman, 2000) wherein teachers, like coaches, are beginning to help students "to learn rather than teaching them" (Whitmore, 2002, p. 8).

\section{Coaching and learning}

Learning is inherent within the coaching process. Numerous coaching texts and studies refer to the implicit nature of learning in coaching which paves the way for the achievement of goals and manifestation of change (Hargrove, 2003; Hurd, 2002; Whitmore, 2002; Whitworth et al., 1998; Wilkins, 2000). In her phenomenological study of nine organisational coaching clients, Hurd (2002) revealed that "coaching creates the conditions for learning and behaviour change" (p. 124) depicting coaching as an on-going cycle of deep learning. Similarly, Whitworth et al. (1998) described coaching as an on-going cycle of action and learning which together combine to create change. Thus a major part in the coach's job is to "deepen the learning" (Whitworth et al., 1998, p. 5). Finally, Hargrove (2003) refers to the learning done in coaching as "transformational" rather than "transactional" (p. 86). In other words, when individuals engage in coaching they undertake a form of deep learning which they integrate into multiple aspects of their lives. In its essence, coaching first "awaken[s] the will to learn" (Loranger, 2001, p. 3) and then, through a learning-partnership between coach and client, it represents powerful learning in action. Clearly, and as Wilkins (2000) emphasised, "the coaching model has implications for educational leadership as a tool for facilitating learning" (p. ii).

The learning that occurs through coaching comes in many forms. It empirically demonstrates itself as a form of incidental, informal, skills-based experiential learning (Moran, 2003) and, at the other end of the spectrum, accentuates learning in terms of shifts in perspectives and challenging "the saboteur," thereby moving past barriers and blocks to success (Creane, 2002). Studies consistently outline the various nature of learning within the coaching process generating a transfer of learning in which theoretical learning is practically applied and integrated into the minds and actions of clients (Skiffington \& Zeus, 2003). In summary, the common thread running through the learning experienced in coaching is creating "learning that endures" (Skiffington \& Zeus, 2003, p. 81) or as Hurd (2002) wrote in the abstract of her study, coaching is "learning for the long haul"; it is "learning for life" (p. i). Once again, it becomes apparent how coaching can provide an effective means for creating active, collaborative, authentic and engaging learning.

Learning is changeable, all-encompassing and ultimately its meaning lies "in the eyes of the beholder." It is an integral part of life reaching not only into the depths of our lives, minds and beings but also into many theoretical and philosophical disciplines and schools of thought. As such, learning can be seen from many vantage points. Although not applicable to the purposes of this paper, it must be acknowledged that a substantial part of learning in coaching has its roots in constructivist schools of thought and psychology as well as learning theory. The repeated links made between coaching and experiential learning accentuate the constructivist nature of coaching. Indeed, coaching closely aligns with a constructivist approach to learning which provides a client-centred, authentic and challenging arena for goal-directed, problem-based learning (Woolfolk, 1998). Furthermore, learner-centred psychological principles acknowledge the influence of cognitive and metacognitive factors, motivational and affective factors, developmental and social factors as well as individual differences in the learning process (McInerney \& McInerney, 1998). These in turn form patterns of occurrence across the coaching literature in the form of behaviourist theory, Gestalt theory, social learning theory 
and developmental psychology. Whilst constructivism, psychology and learning theory have converged to shape the evolution of the coaching process, in the next section only learning theory will be discussed.

\section{Learning theory in coaching}

The influences of learning theory have been established within several coaching studies as well as other coaching related literature. Coaching has been shown to foster and be underpinned by philosophies of adult learning theory and theories in lifelong learning (Grant, 2001a, 2001b; Hurd, 2002; Parsloe, 1992; Skiffington \& Zeus, 2003; Wilkins, 2000). Coaching also appears to draw on sizeable chunks of mentoring theory (Parsloe, 1992; Zachary, 2000). When exploring the process and effects of coaching, experiential learning was also often cited (Hudson, 1999; Hurd, 2002; Kopf \& Kreuze, 1991). Finally, in addition to the use of problem-based learning strategies and self-directed learning, transformational learning was seen to evolve through the coaching process (Duff, 2002; Hargrove, 2003).

\section{Adult learning theory and lifelong learning}

The framework and processes within which coaching occurs align well with adult and lifelong learning theory. Working through a goal-oriented, self-directed and active connection between new learning and life experience, as in adult learning, coaching addresses an individual's need to know and readiness to learn. Reflective of adult learning theory (Knowles, Holton \& Swanson, 1998; Rogers, 1986), by operating from a responsive goal-centred framework, it allows learners to clearly understand the benefits, value and reason for learning, thereby facilitating understanding of what is most useful to real life (Hurd, 2002; Skiffington \& Zeus, 2003). Like adult learning, problem-centred and based on immediate goals, needs and concrete situations, combined with the immediate application of "short bursts of learning activity" (Rogers, 1986, p. 76), coaching takes into account various learning styles such as analogical thinking, trial and error and formation of a meaningful whole (Rogers, 1986). Inherent in this process are also a respect of the adults' already acquired knowledge and experience and the importance of feedback, the latter of which has been highlighted within several studies from the perspectives of clients (Creane, 2002; Hurd, 2002; Paige, 2002).

A number of adult learning theories have contributed to the development of the goal-directed coaching framework and processes with which it is applied. Adapted from Kurt Lewin's (1951) work, Kolb's (1984) cycle of learning illustrates the cyclic interrelationship between concrete experience, observation, conceptualisation and experimentation, as adults encounter meaningful, purposeful and self-directed learning (Skiffington \& Zeus, 2003). This occurs both within adult learning experiences and coaching. Furthermore, the work of other adult learning theories such as Habermas (1978), Daloz (1986) and Mezirow (2000) are also strongly reflected in the coaching process. Habermas's (1978) "domains of learning" can be seen to be mirrored in the outcomes of coaching as clients experience: technical learning of skills and content to reach their goals; practical learning as they become more aware of and enhance their interpersonal relationships; and emancipatory learning, during which they develop heightened self-awareness, self-understanding and transformation in terms of shifts in perspective (Habermas, 1978, cited in Rogers, 1986; International Coach Federation, 1998).

Similarly, Daloz (1986) considered the transformational power of adult learning experiences under the umbrella of effective teaching and mentoring. Of particular interest within his discussions of adults' search for meaning, change and development and educational journey are Daloz's strategies for guiding adults through difficult transition. He explained the importance of providing a vision coupled with the right balance of support and challenge. This is in direct correlation with coaching which is goal- or vision-directed and which fosters support through active listening, feedback and encouragement and creates challenge through accountability, moving the client to reassess assumptions and perceptions (Creane, 2002; Grant, 2001a; International Coach Federation, 2004). 
Thus a combination of high support and high challenge results in maximum growth and ultimately transformation. This kind of transformational learning is uniquely characterised by the work of Mezirow (2000) and will be discussed in the following section.

\section{Transformational learning}

The transformational value of coaching has been recognised by both coaching authors and researchers alike (Duff, 2002; Hargrove, 1995, 2003). Within his study of clients' perspectives of personal coaching, Duff (2002) examined the potential of coaching to "facilitate a transformational learning experience" (p. 2) and defined coaching contexts as a "unique learning sanctuary" characterised by a convergence of "mutual trust, learning ethic and creativity" (pp. 3-4). In comparison, Hargrove (2003) explained that transformational learning in coaching occurs through a personal context involving the planning of strategies and implementation of actions, of which the results are monitored and assessed. He describes transformational learning as a triple loop process that moves through levels of skill and capability development, reshaping of patterns of thinking and behaviour and ultimately results in a transformation of clients' personal contexts and perspectives of themselves (Hargrove, 1995).

From the perspective of adult learning theory and education for social change, Mezirow (2000) identified different components involved within the transformational learning process: meaningful contexts; instrumental and communicative learning, which focuses on problem solving and environment manipulation as well as inferred meaning in communication; and, reflective discourse, which acknowledges the role of reflective, emotionally mature dialogue in facilitating transformation. From this discussion, a relationship between Duff (2002), Hargrove (1995) and Mezirow (2000) can be drawn whereby active learning and a communicative relationship are deemed essential elements within the transformation process. Interestingly, these elements are reflected within the core coaching processes discussed earlier in this paper.

Mezirow (2000, p. 22) also described specific phases of transformation:

1. A disorienting dilemma

2. Self-examination with feelings of fear, anger, guilt or shame

3. A critical assessment of assumptions

4. Recognition that one's discontent and the process of transformation are shared

5. Exploration of options for new roles, relationships and actions

6. Planning a course of action

7. Acquiring knowledge and skills for implementing one's plans

8. Provisional trying of new roles

9. Building competence and self-confidence in new roles and relationships

10. A reintegration into one's life on the basis of conditions dictated by one's new perspective

When reflecting on coaching as a whole, there is an unmistakable mirror image of Mezirow's (2000) stages in transformation in the framework and processes described earlier within the coaching literature. Clients typically come to personal coaching with a need to improve on aspects of their lives or work. They then proceed to assess their current realities and assess their underlying beliefs. Next, they brainstorm the possibilities for change, after which they plan and implement a course of action. During this stage, they episodically acquire the skills and knowledge needed to reach their goals and begin "test driving" their new roles or strategies. Confidence and competence are gradually built and, ultimately, the transformation becomes a natural state of being. Thus it is clear that the coaching process has strong links with Mezirow's (2000) stages in transformation. 


\section{Experiential learning}

Experiential learning is repeatedly linked to the foundations and success of the coaching process. Indeed, it forms the arena in which learning is applied and developed, providing concrete substance and problem-based discovery. Kolb's (1984) work in experiential learning clearly depicts the facets of coaching that interlink personal development, work and education with experiential learning. In both experiential learning and coaching, personal development assumes prime position. Directly leading to and facilitating personal development are the contributions of education or learning and finally work or life provides a context and springboard for coaching, and thereby, experiential learning to occur.

Reflected within the coaching process, Kolb's (1984) theory also proposes a synthesis of adaptive processes, the foundations of which lie in scientific enquiry and problem-solving, decision-making and creative process. Moreover, Kolb stipulated that "there may be great payoff in the integration of findings from these specialised areas into a single general adaptive model" (p. 33). Comparing the coaching framework and processes with Kolb's basic adaptive processes, it seems that coaching provides such integration. Notably, at the top of and surrounding this adaptive model is the problem and at the opposite end is answer-seeking. This can be directly correlated with the client entering coaching with a need for change and using coaching to uncover and discover the answers that will bring about this change. These two points can be seen to act as "creative tension" (Hargrove, 1995, p. 90) in coaching, which pulls the client from his/her current reality towards her/his future vision. Then, between these two points, Kolb (1984) identified "question asking," the dominant communicative coaching process, and "portrayal of knowledge" which, in turn, reflects the learning base that clients build progressively. Finally, this is facilitated by processes like those explained within the goaldirected coaching framework. At the centre of the model is the coaching/learning cycle. Lastly, Kolb (1984) outlined a structure for the underlying process of experiential learning and linked it to various forms of knowledge. While this model is similar to the learning cycle outlined above, it also highlights the role of intention in the experiential learning process, another shared cornerstone within coaching.

Hurd's (2002) discussions with organisational coaching clients highlight the importance of experiential and contextual learning demonstrating how clients actively engage in learning experiences within a context that is real and of immediate concern. Furthermore, the problem-solving capacity of coaching is evidenced in studies like that of Ellinger and Bostrom (1999), within which managerial coaches, explicitly encouraged their coaches to "think for themselves" rather than be directed, thereby developing responsibility and problem-solving skills. Similarly, Shields' (1997) study of "real" learning in American high schools showed that within experiential learning, problem-solving and reasoning skills are used and developed in a cooperative, team-oriented setting resulting in concrete learning. Thus coaching provides an opportunity to learn through experience (Hudson, 1999; Hurd, 2002) and, as Kopf and Kreuze (1991) proposed, an experiential learning model forms the foundation for coaching practice.

\section{Mentoring theory}

The dimensions of the coaching relationship and dialogue process are particularly reflective of mentoring theory. Through a relationship based on personal support, mentoring provides assistance and feedback and fosters the learning and development of mentees (Ehrich, 1999). Through a process combining similar elements of encouragement, self-management, support and evaluation (Parsloe \& Wray, 2000), both coaching and mentoring are learner-centred with learning at their core. In addition, they utilise conversation processes such as: questioning, reforming statements, summarising, listening reflectively and personal reflection in order to evoke learning (Zachary, 2000). Furthermore, one particular aspect of mentoring also reflected within coaching literature is the reciprocal relationship between mentor and mentee (Ehrich, 1999). Coaching literature indicates that while clients learn, coaches do too (Zeus \& Skiffington, 2002) and this in turn is reflected in the words of Freire (1990) that "whoever teaches learns in the act of teaching, and whoever learns teaches in the act of learning" 
(p. 31). Lastly, similar to the aims of the mentoring process, Skiffington and Zeus (2003) targetted the ultimate learning outcome of the coaching process as being when "finally, the learner internalises the 'teaching function' of the coach and becomes his or her own teacher" (p. 22). Thus, despite the hierarchical differences in the learning relationship of mentoring and the commitment of coaching to goal-directed action as discussed earlier, mentoring theory provides a basis for understanding the coaching process and how it creates, reciprocates and supports learning for the long run.

\section{A combined coaching-learning model}

In suggesting a combined coaching-learning model (see Figure 2), a shift in educational approach is required. Currently in formal educational contexts such as schools, colleges and universities, learning outcomes are dictated by a curriculum which is then delivered "unto" students and results in the achievement of educational goals as set down by a regulatory board. In contrast, a model for learning in which a "coach approach" is adopted would place students' personal goals at its pinnacle. Thus, as in adult learning, a student's individual need to know and readiness to learn would dictate their development towards their goals and in turn deliver learning outcomes. This model would be brought alive through a transformational learning-alliance between coach and learner, thereby providing a goal-directed, action-based coaching framework facilitated through processes such as active listening, powerful questioning, problem-solving, self-regulation and observation. This model is graphically represented in Figure 2.

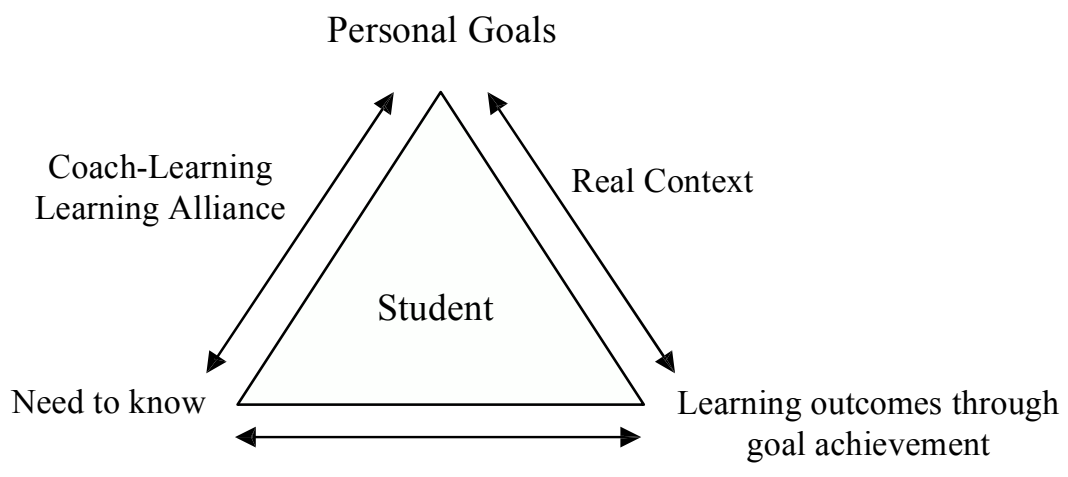

Figure 2: Coaching-Learning Model

Such a proposal, a bold move away from the traditional controls of a predetermined curriculum and a synthesis of both coaching and learning theory as outlined above, has the potential to, if adopted in its entirety, challenge educators in schools, colleges and universities at their core and, with that, revolutionise the face of such institutions. However, it must be emphasised that even a partial adoption of a coaching-learning model has the potential to provide a unique balance between structure and flexibility and has the capacity of meeting the needs of individual learners and succeeding in the delivery of truly active, collaborative, authentic and engaging learning.

\section{Conclusion}

In their discussion of "good" learning which draws on research from all sectors of education, Collins, Harkin and Nind (2002) highlighted that in order to foster effective learning, "it should be transformative, active, interactive, intrinsically motivating and lifelong" (p. 11). It is interesting to note that these factors are strongly reflected in coaching processes and outcomes evidenced within empirical studies, technical literature and within the above discussion of learning theory employed within coaching practice. As the body of literature surrounding coaching is still in its embryonic stages, claims about what coaching is, does and how it works are as yet largely unsubstantiated. 
Despite this, by drawing upon the limited body of evidence-based coaching knowledge from various contexts, this paper has evidenced how learning indeed appears to be at the heart of coaching. Underpinning the goal-directed, action-based framework of coaching which combines powerful dialogue within a supportive yet challenging arena are the concepts and approaches encouraged within adult and lifelong learning, transformational learning, experiential learning and mentoring theory. Through a synthesis of learning theory contained within a holistic model that provides a practical bridge between many previously mutually exclusive disciplines and schools of thought an effective approach to teaching and learning is therefore proposed.

Despite the learning potential of coaching, educational contexts are yet to significantly explore personal coaching as a whole-package approach to learning. Thus, the value of coaching as a learning process in itself remains uncharted territory within educational settings. Through this discussion of personal coaching, its governing framework and essential processes, the roots of which stem from a firm foundation of learning theory and culminate in a unique model for learning, this paper intends to challenge the limited awareness and use of personal coaching within educational contexts.

Furthermore, this paper aims to spark further exploration and empirical research into personal coaching within various educational contexts in the aim of determining its impact upon learning outcomes. At present in coaching literature, learning is seen largely as a means to end, as the precursor to change. Yet from an educational perspective, learning can be seen as an end in itself. The goaldirected, self-regulated and self-reflective model for change that coaching provides within a collaborative partnership between coach and client has the potential to be as a model for effective learning, as it creates a strong learning alliance that transcends the limitations of transactional learning. It is for this reason that educational settings must not miss or delay joining the coaching "bandwagon," Indeed, it is in the best interests of both educators and their students to further explore, experiment with and potentially embrace personal coaching as a model for effective learning.

\section{References}

Bagnall, D. (1999, March 30). Select Companies. Bulletin with Newsweek, 117 (6167). Australian Consolidated Press, Sydney, Australia.

Bono, J. Purvanova, R.K, \& Towler, A. (2004). Summary of responses for coaching survey: Technical report. University of Minnesota, Minnesota.

Campbell, M.A., \& Gardner, S. (2003). A pilot study to assess the effects of life coaching with Year 12 students. Paper presented at the First Australian Conference on Evidenced-Based Coaching, July, 2003, Sydney, Australia.

Collins, J., Harkin, J., \& Nind, M. (2002). Manifesto for learning. London: Continuum.

Costa, A.L. (1992). An environment for thinking. In C. Collins, \& J. N. Mangieri, (Eds.), Teaching thinking: An agenda for the $21^{\text {st }}$ century (pp. 169-181). New Jersey, NJ: Lawrence Erlbaum.

Costa, A.L. (2000). Mediative environments: Creating conditions for intellectual growth. In A. Kozalin, \& Y. Rand, (Eds.), Experience of mediated learning: An impact of Feuersteins's theory in education and psychology (pp. 34-44). Amsterdam, The Netherlands: Elsevier Science.

Costa, A.L. \& Garmston, R.J. (1994). Cognitive coaching: A foundation for renaissance schools. Norwood, MA: Christopher-Gordon.

Creane, V.E. (2002). An exploratory study of personal coaching from the client's perspective. Unpublished doctoral dissertation, California Institute of Integral Studies, San Francisco, USA.

Daloz, L.A. (1986). Effective teaching and mentoring: Realizing the transformational power of adult learning experiences. San Francisco, CA: Jossey-Bass. 
Dansinger, S. (2000). Academic coaching for the gifted learner. (ERIC Document Reproduction Service No. ED444278).

Duff, P.J.J. (2002). The role of personal coaching in enhancing leadership confidence and learning capability. Unpublished Masters dissertation, Royal Roads University, British Columbia, Canada.

Ehrich, L.C. (1999). Mentoring: Pros and cons for HRM. Asia Pacific Journal of Human Resources, 37(3), 92-107.

Ellinger, A.D., \& Bostrom, R.P. (1999). Managerial coaching behaviours in learning organizations. The Journal of Management Development, 18(9), 752-771.

Evered, R.D., \& Selman, J.C. (1989). Coaching and the art of management. American Management Association in Organizational Dynamics, 18(2), 16-32.

Freire, P. (1990). Pedagogy of freedom: Ethics, democracy and civic courage. New York: Rowman and Littlefield Publishers.

Gale, J., Liljenstrand, A., Pardieu, J., \& Nebeker, D.M. (2002). Coaching: Who, what, where, when and how. Coaching World - International Coach Federation, 93.

Garmston, R. (1993, October). Reflections on cognitive coaching. Educational Leadership, pp. 57-60.

Grant, A. M. (2001a). Towards a psychology of coaching. Coaching Psychology Unit, School of Psychology, University of Sydney, New South Wales, Australia.

Grant, A.M. (2001b). Towards a psychology of coaching: The impact of Coaching on metacognition, mental health and goal attainment. Unpublished doctoral dissertation, Macquarie University, Sydney, Australia.

Grant, A.M. (2003a). Keeping up with the cheese! Research as a foundation for professional coaching of the future. Keynote presentation of the International Coach Federation Conference Symposium on Research and Coaching, November, 2003, Denver, Colorado.

Grant, A.M. (2003b). The impact of life coaching on goal attainment, metacognition and mental health. Social Behavior and Personality, 31(3), 253-264.

Griffiths, K. (2006). Personal coaching: A model for effective learning. Journal of Learning Design, 1(2), 55-65. doi:10.5204/jld.v1i2.17

Griffiths, K. \& Campbell, M. (2009). Discovering, applying and integrating: The process of learning in coaching. International Journal for Evidence Based Coaching and Mentoring, 7(2), 16-31.

Habermas, J. (1978). Knowledge and human interest. London: Heinemann Educational.

Hargrove, R. (1995). Masterful coaching: Extraordinary results by impacting people on the way they think and work together. San Francisco, CA: Jossey-Bass.

Hargrove, R. (2003) Masterful coaching (rev. ed.). San Francisco, CA: Jossey-Bass Pfeiffer.

Hogan, M. (2004) Executive coaching: An answer for school principals? The Practising Administrator, 3, pp. 4-6.

Hollum, A. \& Gahala, J. (2001). Critical issue: Using technology to enhance literacy instruction. (ERIC Document Reproduction Service No. ED480229).

Hudson, F.M. (1999). The handbook of coaching: A comprehensive resource guide for managers, executives, consultants, and human resource professionals. San Francisco, CA: Jossey-Bass.

Hurd, J. L. (2002). Learning for life: A phenomenological investigation into the effect of organizational coaching on individual lives. Unpublished doctoral dissertation, Union Institute and University Graduate College, USA. 
International Coach Federation (1998). Client survey results and press release. Retrieved from http://www.coachfederation.org/files/includes/docs/008ICFClientSurveyResults1998.doc

International Coach Federation (2004). Coaching core competencies. Retrieved from http://www.coachfederation.org/files/FileDownloads/CoreCompetencies.pdf

Joy, K.L. (2001). The archetypes of coaching: Using organic inquiry to learn about successful professional personal coaching. Unpublished Masters dissertation, California Institute of Integral Studies, San Francisco, California.

Keenan, T.P. \& Braxton-Brown, G. (1991). Techniques: Coach, consultant, critic, counselor: The multiple roles of the responsive facilitator. Journal of Adult Education, 19(2), inset.

Killion, J. (2002) Soaring with their own life coach. Journal of Staff Development, 23(2), 19-22.

Knowles, M.S., Holton III, E.F., \& Swanson, R.A. (1998). The adult learner (5th ed.). Houston: Gulf.

Kolb, D.A. (1984). Experiential learning: Experience as the source of learning and development. New Jersey, NJ: Prentice-Hall.

Kopf, J.M., \& Kreuze, J.G. (1991). Achieving performance excellence: training the trainer. Mid American Journal of Business, 6(1), 23-26.

Lewin, K. (1951). Field theory in social science. New York: Harper.

Loranger, P. (2001) Awakening the will to learn: A three dimensional look at a two dimensional curriculum - a paradigm shift. Edmonton, Canada: Synlogic.

McInerney, D.M., \& McInerney, V. (1998). Educational psychology: Constructing learning (2nd ed.). Sydney, Australia: Prentice Hall.

Mezirow, J. (2000). Learning as transformation: Critical perspectives on a theory in progress. San Francisco, CA: Jossey-Bass.

Moran, L. (2003). A case study of informal learning among production workers. Unpublished doctoral dissertation, Columbia University Teachers College, USA.

Olivero, G. Bane, K.D., \& Kopelman, R.E. (1997). Executive coaching as a transfer training tool: Effects on productivity in a public agency. Public Personal Management, 26(4), 461-469.

Paige, H. (2002). Examining the effectiveness of executive coaching on executives. International Education Journal, 3(2), 61-70.

Parsloe, E. (1992). Coaching, mentoring and assessing: A practical guide to developing competence. London: Kogan Page.

Parsloe, E., \& Wray, M. (2000). Coaching and mentoring: Practical methods to improve learning. London: Kogan Page.

Passman, R. (2000). Pressure cooker: Experiences with student centred teaching and learning in highstakes assessment environments. Paper presented at the Annual Meeting of the Southwest Research Association, Dallas, TX, January 27-29. (ERIC Document Reproduction Service No. ED440146)

Quick, J.C., \& Macik-Frey, M. (2004). Behind the mask: coaching through deep interpersonal communication. Consulting Psychology Journal: Practice and Research, 56(2), 67-74.

Results Coaching Systems. (2004). The history of coaching. Retrieved from $\mathrm{http}: / / \mathrm{www}$.workplacecoaching.com/resources.html

Richardson, C. (2000). Take time for your life. London: Bantam Books.

Rogers, A. (1986). Teaching adults. Milton Keynes, UK: Open University Press. 
Shields, S. (1997). A profile of the commonalities and characteristics of contextual teaching as practiced in selected educational settings. Unpublished doctoral dissertation, Oregon State University, Oregon.

Skiffington, S., \& Zeus, P. (2003). Behavioral coaching. Sydney, Australia: McGraw Hill.

Snyder, S. (1996). Teachers and change: Teachers explore the influences affecting their ability to adopt the role of facilitator in a multimedia laboratory. Unpublished doctoral dissertation, Hofstra University, New York.

Weiser, A. (1998, May). Too much tutoring. Parenting, 12(4), p. 163.

Whitmore, J. (2002). Coaching for performance (3rd ed.). London: Nicholas Brealey.

Whitworth, L., Kimsey-House, H., \& Sandahl, P. (1998). Co-active coaching. Palo-Alto, CA: Davies Blade.

Wilkins, B.M. (2000). A grounded theory study of personal coaching. Unpublished doctoral dissertation, University of Montana, Montana.

Woolfolk, A.E. (1998) Educational psychology (7th ed.). Boston, MA: Allyn and Bacon.

Zachary, L.J. (2000). The mentor's guide: Facilitating effective learning relationships. San Francisco, CA: Jossey-Bass.

Zeus, P., \& Skiffington, S. (2002). The coaching at work toolkit: A complete guide to techniques and practices. Sydney, Australia: McGraw Hill.

\section{Acknowledgements}

I would like to acknowledge and thank Lisa Ehrich and Annah Healy for their guidance in conceptualising and structuring the first versions of these ideas both in my mind and in words on paper.

(C) Copyright Kerryn Griffiths [2015] 